University of Nebraska - Lincoln

DigitalCommons@University of Nebraska - Lincoln

USDA National Wildlife Research Center - Staff Publications
U.S. Department of Agriculture: Animal and Plant Health Inspection Service

2021

\title{
Understanding tolerance for an invasive species: An investigation of hunter acceptance capacity for wild pigs (Sus scrofa) in Texas
}

Hailey E. McLean

Tara L. Teel

Alan Bright

Lauren M. Jaebker

John M. Tomecek

See next page for additional authors

Follow this and additional works at: https://digitalcommons.unl.edu/icwdm_usdanwrc

Part of the Natural Resources and Conservation Commons, Natural Resources Management and Policy Commons, Other Environmental Sciences Commons, Other Veterinary Medicine Commons, Population Biology Commons, Terrestrial and Aquatic Ecology Commons, Veterinary Infectious Diseases Commons, Veterinary Microbiology and Immunobiology Commons, Veterinary Preventive Medicine, Epidemiology, and Public Health Commons, and the Zoology Commons

This Article is brought to you for free and open access by the U.S. Department of Agriculture: Animal and Plant Health Inspection Service at DigitalCommons@University of Nebraska - Lincoln. It has been accepted for inclusion in USDA National Wildlife Research Center - Staff Publications by an authorized administrator of DigitalCommons@University of Nebraska - Lincoln. 


\section{Authors}

Hailey E. McLean, Tara L. Teel, Alan Bright, Lauren M. Jaebker, John M. Tomecek, Maureen G. Frank, Rachael L. Connally, Stephanie A. Shwiff, and Keith M. Carlisle 


\title{
Understanding tolerance for an invasive species: An investigation of hunter acceptance capacity for wild pigs (Sus scrofa) in Texas
}

\author{
Hailey E. McLean ${ }^{\text {a,b, }}$, Tara L. Teel ${ }^{\mathrm{a}}$, Alan D. Bright ${ }^{\mathrm{a}}$, Lauren M. Jaebker ${ }^{\mathrm{a}, \mathrm{b}}$, John M. Tomecek ${ }^{\mathrm{c}}$, \\ Maureen G. Frank ${ }^{c}$, Rachael L. Connally ${ }^{c}$, Stephanie A. Shwiff ${ }^{b}$, Keith M. Carlisle ${ }^{\mathrm{a}}$ b \\ ${ }^{a}$ Department of Human Dimensions of Natural Resources, Warner College of Natural Resources, Colorado State University, 1480 Campus Delivery, Fort Collins, CO, \\ 80523, USA \\ ${ }^{\mathrm{b}}$ National Wildlife Research Center, United States Department of Agriculture, Animal and Plant Health Inspection Service, Wildlife Services, Fort Collins, CO, 80521, \\ USA \\ ${ }^{\mathrm{c}}$ Department of Rangeland, Wildlife, and Fisheries Management, Texas A\&M University, College Station, TX, 77843, USA
}

\section{A R T I C L E I N F O}

\section{Keywords:}

Tolerance

Wildlife acceptance capacity

Feral swine

Invasive species management

Human-wildlife interactions

Human dimensions

\begin{abstract}
A B S T R A T
Invasive species and their establishment in new areas have significant impacts on the ecological, economic, and social well-being of our planet. Wild pigs (Sus scrofa) are one of the world's most formidable invasive species, particularly in the United States. They cause significant damage to agriculture and ecosystems, and can transmit diseases to livestock, wildlife, and people. There is an inherent social dimension to the issue of wild pigs due in part to the fact that people hunt them. Hunting contributes to both the control and spread of this species. The objectives of this study were to: 1 ) determine hunters' overall tolerance for wild pigs; and 2) identify what factors predict hunters' tolerance. Results obtained from a survey of Texas hunters in 2019 indicated that $83 \%$ of hunters had a low level of tolerance for wild pigs, with approximately $63 \%$ preferring to see the population reduced and $20 \%$ preferring to see the population completely removed. Fourteen percent preferred that wild pig numbers remain the same, and $2 \%$ preferred to see numbers increase. Results from regression analysis indicated that approximately $53 \%$ of the variance in tolerance for wild pigs was explained by motivations and preferences for hunting wild pigs, level of concern for wild pig damage, and overall attitudes toward wild pigs. Results of this research are useful in expanding current knowledge about human tolerance for wildlife, including those species that are non-native and invasive, and in identifying important factors affecting how hunters perceive and interact with wild pigs. Study findings are also helpful in informing the development of effective and socially acceptable management plans for wild pigs, as well as communication efforts aimed at influencing hunters' attitudes and behaviors in the wild pig management context.
\end{abstract}

\section{Introduction}

Wild pigs (Sus scrofa) are native to large parts of Europe, Asia, and North Africa, but are non-native to the New World (Mayer and Brisbin, 2008). In the 1500 s, they were introduced to North America by early Spanish explorers as a food source (Belden and Frankenberger, 1977). They cause considerable damage to ecosystems and agriculture and can transmit diseases to wildlife, livestock, and people. With their wide-ranging impacts on agriculture and ecosystems, the International Union for Conservation of Nature named wild pigs as one of the 100 "World's Worst" invaders (Lowe et al., 2000). In addition, their early maturation and high fecundity rates, along with their adaptability, have contributed to wild pigs being among the most widely distributed large mammals in the world (Oliver and Leus, 2008).

In the United States, wild pigs have been reported in at least 35 states, with a population estimated at over 6 million and growing (Fig. 1) (USDA, 2019). Wild pigs cause an estimated $\$ 1.5$ billion dollars in agricultural damages and management costs each year (Bevins et al., 2014; Pimental, 2007), but this estimate is likely much greater due to unreported damages, inflation, and the continued growth of wild pig populations in the United States. The state with the largest population of wild pigs is Texas, where they are present in all but one county (Kinsey,

\footnotetext{
* Corresponding author. Department of Human Dimensions of Natural Resources, Warner College of Natural Resources, Colorado State University, 1480 Campus Delivery, Fort Collins, CO, 80523, USA.

E-mail address: hailey.mclean@colostate.edu (H.E. McLean).
} 
2020) and their population was estimated at 2.5 million in 2013 (Lewis et al., 2019). Reflective of the large number of wild pigs and size of the state's crop industry, one study found that Texas suffered the greatest economic loss from wild pigs to six high value crops compared to 11 other states with wild pig problems (Anderson et al., 2016). Another study found that Texas producers lost an additional $\$ 116$ million in 2018 from wild pig damage to only four crop types (McKee et al., 2020). These studies illustrate the overall magnitude and severity of agricultural and economic impacts from wild pigs in Texas.

\subsection{The role of hunters}

Regardless of their negative impacts as an invasive species, some stakeholder groups, including hunters find value in wild pigs. For example, research has shown that hunters consider wild pigs as a resource for subsistence and recreational hunting in Brazil (Desbiez et al., 2011; Rosa et al., 2018), Algeria (Boumendjel et al., 2016), Japan (Ueda and Kanzaki, 2005), and Hawaii, where the species is also acknowledged by locals as integral to hunting cultures and heritages (Pejchar and Mooney, 2009; Weeks and Packard, 2009). More broadly in the United States, hunters also play a unique role in both the control and spread of wild pigs. Although hunting may be employed to aid in population management, it may also promote interest in maintaining or establishing populations for hunting activities (Caudell et al., 2016; SEAFWA-WHWG, 2016; Zivin et al., 2000). In this regard, hunters have been implicated in translocating wild pigs to new areas for the purpose of sport hunting (Grady et al., 2019), thereby contributing to the introduction and spread of this invasive species. However, hunters are also critical to the success of wild pig management efforts, not only because they aid in controlling wild pig populations, but also because they serve as key stakeholders in wildlife policy decisions (Organ et al., 2012).

Management of wild pigs is a controversial issue in some regions because government agency personnel, as well as various stakeholders, have diverse and strongly held attitudes toward the species (Keuling et al., 2016; Miller, 1993). Historically, efforts made by government agencies to manage wild pigs have been met with backlash from hunters who were not in favor of total eradication (Maguire et al., 1997; Peine and Farmer, 1990; Pejchar and Mooney, 2009; Weeks and Packard, 2009). Given that wild pigs' geographic distribution in the United States has nearly tripled since 1982 (Corn and Jordan, 2017), partly due to intentional translocations for hunting (Bevins et al., 2014; Caudell et al., 2016), states have implemented a variety of policies to manage wild pig range expansion, such as restrictions on their transport. However, the success of such policies depends, in part, on their level of public awareness and support, including among hunters who may have an interest in maintaining wild pig populations (Grady et al., 2019).

\subsection{Research gaps and study objectives}

Despite the need for understanding the human dimensions of hunterwild pig interactions, to date little research exists on hunters' tolerance for wild pigs and their preferences and motivations for hunting the species in the United States (Beasley et al., 2018). The concept of tolerance has been frequently applied in human dimensions of wildlife research to understand human interactions with native wildlife species that are in conflict with people. Tolerance toward wildlife can be defined as an individual's or group's ability and willingness to accept the costs of living with wildlife and desire for positive effects that arise from interactions with wildlife (Bruskotter et al., 2015; Carpenter et al., 2000; Decker and Purdy, 1988; Kansky et al., 2016; Lischka et al., 2019). It can encompass both attitudinal (e.g., positive feelings toward a species) and behavioral (e.g., stewardship behaviors) dimensions (Bruskotter et al., 2015). Highlighting the significance of the concept, Sutherland et al. (2009) noted that one of the 100 scientific questions of greatest importance to global biodiversity conservation is "what factors shape human (in)-tolerance of the presence and activities of wild animals, especially where those animals induce human-wildlife conflict?" (p. 565). A common indicator of tolerance is wildlife acceptance capacity, defined as the maximum wildlife population level in an area that is acceptable to people (Bruskotter and Fulton, 2012; Decker and Purdy, 1988; Inskip et al., 2016; Struebig et al., 2018). Wildlife acceptance capacity is commonly measured at the individual level by asking stakeholders whether they believe that a wildlife population should increase, decrease, or remain the same size (Decker and Purdy, 1988; Riley and Decker, 2000; Skupien et al., 2016; Slagle et al., 2013).

The tolerance concept has been increasingly applied in conservation to understand human interactions with native predators such as wolves, bears, and large cats, both in the United States and in other parts of the world (e.g., Bruskotter and Fulton, 2012; Inskip et al., 2016; Lischka et al., 2019; Riley and Decker, 2000; Majić et al., 2011). The concept has also been applied in relation to other species such as the American alligator (Alligator mississippiensis) (Skupien et al., 2016), white-tailed deer (Odocoileus virginianus) (Lischka et al., 2008), beaver (Castor canadensis) (Morzillo and Needham, 2015), and free-roaming cats (Felis catus) (Wald and Jacobson, 2013) in the United States. While previous studies have provided valuable insight into human tolerance across a host of species, research is lacking on tolerance for invasive species such
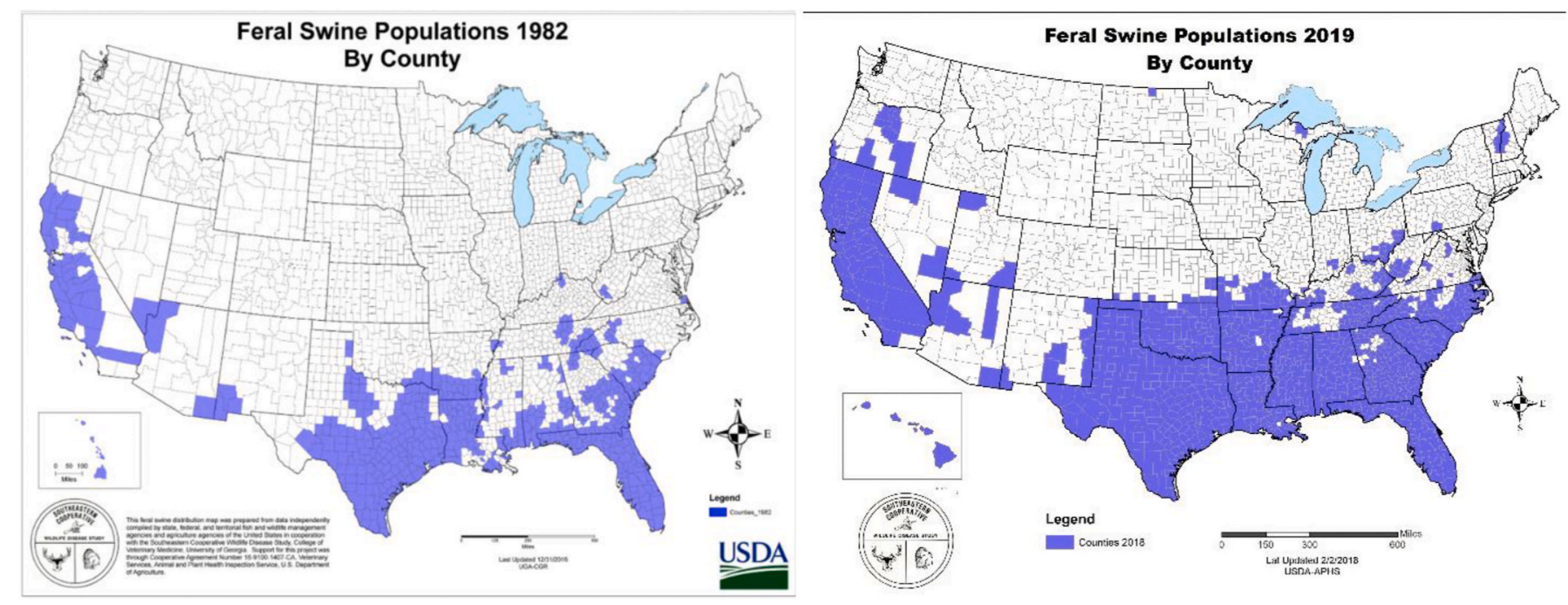

Fig. 1. Growth in wild pig density at the county level across the United States from 1982 (left) to 2019 (right) (USDA, 2019). 
as wild pigs.

In response to the need for more research in this area, our research objectives were to: 1 ) determine hunters' overall tolerance for wild pigs; and 2) identify what factors predict hunters' tolerance. We drew upon prior research with other species, indicating that tolerance is related to prior experience, perceptions of risks and benefits, and attitudes toward the species, as well as socio-demographic characteristics (e.g., Inskip et al., 2016; Kansky et al., 2016; Lischka et al., 2019; Skupien et al., 2016; Struebig et al., 2018; Wald and Jacobson, 2013). Additional factors not investigated in previous studies but deemed relevant in the context of our study included motivations and preferences for hunting wild pigs, and ownership or management of land in Texas. Our research was intended to help expand current knowledge about human tolerance for wildlife, including those species that are non-native and invasive, and identify important factors affecting how hunters perceive and interact with wild pigs. In addition, study findings would aid in informing effective and socially acceptable management plans for wild pigs, as well as communication and outreach efforts aimed at influencing hunters' attitudes and behaviors in the context of wild pig management.

\section{Methods}

\subsection{Sampling and data collection}

Data were collected using an online survey (Appendix A) administered under the auspice of the Texas A\&M AgriLife Extension Service via Qualtrics online survey platform (Provo, Utah). The sample was provided by the Texas Parks and Wildlife Department (TPWD) and consisted of all individuals, including residents and nonresidents, who purchased a Texas hunting license for the 2018-2019 hunting year and had an email address associated with their records $(n=169,619)$. A general hunting license (not specific to wild pigs) was required to hunt wild pigs in Texas at the time of survey administration. Wild pigs are not managed as a game animal (i.e., there is no regulated hunting season or take limit) and landowners have legal ownership of them in Texas (TPWD, 2020). The survey was sent to individuals via email on June 4, 2019. Two reminder emails were sent to participants on June 7 and 10, 2019 and the survey closed on August 12, 2019. This study was approved by the Institutional Review Board (IRB) of Texas A\&M University (IRB reference number: 083112).

\subsection{Measurement of key concepts}

\subsubsection{Tolerance for wild pigs}

Tolerance was measured using an item intended to elicit respondents' preferences for future changes to the wild pig population size in the state of Texas, also known as wildlife acceptance capacity (Decker and Purdy, 1988; Riley and Decker, 2000; Skupien et al., 2016; Slagle et al., 2013). Respondents identified their preferences by indicating whether they wanted the population to be completely removed, reduced, remain the same, or increased.

\subsubsection{Prior experience with wild pigs}

Two types of experiences with wild pigs were measured using two distinct items. First, experience with hunting wild pigs was measured by asking respondents, "Which types of animals do you hunt in Texas?" (the variable was recoded to yes/no to indicate if "wild pigs" was selected from the categories provided). Second, experience with wild pig damage was measured by asking respondents who stated that they owned or managed land in Texas, "Please mark all of the areas in which wild pigs had negative impacts on your property in the past year" (the variable was recoded to yes/no to indicate if they had experienced negative impacts in at least one area on their property).

\subsubsection{Risk perceptions and benefits}

We examined respondents' level of concern for wild pig damage with a set of 12 items. Concern can be conceptualized as an emotional construct that includes feelings of worry and anxiety, which are often associated with risk perceptions (Burger et al., 1998; Gore et al., 2006). Perceived risks represent the extent to which a person identifies a risk from a specific source (Siegrist and Cvetkovich, 2000; Sjöberg, 2000). The 12 items consisted of crop losses, stored commodity losses, damage to pastures, damage to wetlands, habitat degradation, damage to water, damage to personal property, loss of land value, loss of lease value, livestock injury or disease, wildlife competition or predation, and human disease or injury. For each type of damage, respondents rated their level of concern on a scale from $1=$ "no concern" to $5=$ "very high level of concern." Tangible benefits (i.e., monetary benefits) were measured with two items associated with wild pig hunting-related activities. The first item asked respondents, "Have you ever trapped and sold live wild pigs?" (yes/no) and the second asked, "Did you provide any wild pig guide or outfitting services to paying hunters in 2018?" (yes/no).

\subsubsection{Attitudes toward wild pigs}

Attitudes toward wild pigs were measured with a set of seven belief statements, on a scale from $1=$ "strongly disagree" to $5=$ "strongly agree." An attitude is defined as a favorable or unfavorable disposition toward an issue, object, person, etc. that arises from one's beliefs. The latter, according to attitude theory, are cognitions that reflect what people think to be true but are not necessarily based on fact (Fishbein and Ajzen, 2010). The seven items included four positive statements: "Wild pigs increase my overall quality of life," "Wild pigs are a valuable resource for recreation, meat, or income in Texas," "Overall, my feelings about wild pigs in Texas are generally positive," and "Wild pigs have the right to exist wherever they may occur." The item set also contained three negative statements: "The harm caused by wild pigs outweighs any benefits of having them in Texas," "Wild pigs do not belong in Texas," and "Wild pigs are a nuisance."

\subsubsection{Socio-demographic characteristics}

Socio-demographic characteristics included Texas residency (item recoded to yes/no based on ZIP code of primary residence), age (recoded based on birth year), gender, highest level of education, race/ethnicity, and average household income.

\subsubsection{Motivations for hunting wild pigs}

Motivations for hunting were measured with a set of five items. Respondents who stated that they had hunted wild pigs in Texas were asked to indicate the importance $(1=$ "not at all important" to $5=$ "very important") of each motivation, including meat, trophies (e.g., skull), recreation, controlling wild pig populations, and controlling wild pig damage.

\subsubsection{Preferences for hunting wild pigs}

Preferences for hunting wild pigs were measured with a set of four belief statements. These included, "I prefer hunting wild pigs even when other animals are available for me to hunt," "I started hunting wild pigs before I became interested in hunting other animals," "I devote more time to hunting wild pigs than other animals," and "I only purchase my hunting license to hunt wild pigs." Preferences were measured on a 5point scale from 1 = "strongly disagree" to 5 = "strongly agree."

\subsubsection{Land ownership or management}

Land ownership or management was measured with the following item: "Do you own or manage land in Texas?" (yes/no).

\subsection{Data analysis}

We entered and analyzed data in SPSS (Chicago, Illinois). For our 
first objective, we examined descriptive statistics to determine hunters' overall tolerance for wild pigs. Descriptive statistics were also examined to understand general patterns across independent measures. For our second objective, we conducted reliability analyses to examine the internal consistency of scales for level of concern, attitudes, and preferences for hunting wild pigs. For scales yielding a Cronbach's alpha $(\alpha)$ greater than 0.65 , indicating acceptable measurement reliability (Vaske, 2008), we computed composite scores by averaging responses for items comprising each scale.

To build a parsimonious model to predict tolerance, we first conducted bivariate correlation analyses to investigate relationships between tolerance and our full suite of independent variables. Pearson's correlation coefficient $(r)$ was used for continuous independent variables, while the point-biserial correlation $\left(r_{\mathrm{pb}}\right)$ coefficient was used for dichotomous independent variables. We used an alpha level of $p<0.05$ for statistical significance and relied on effect sizes to determine the practical significance of findings (Cohen, 1988; Vaske, 2008). Variables that had a medium or large relationship with tolerance $\left(r\right.$ or $\left.r_{\mathrm{pb}}>0.25\right)$ were selected for inclusion in our predictive model. We tested this model with a multiple linear regression analysis. Prior to modeling, we assessed multicollinearity by examining the bivariate correlations among predictor variables. Where $r>0.50$, we inspected Variance Inflation Factor (VIF) values. If VIF values were $>5$, the variable with the weaker correlation with tolerance was removed (Zar, 1999).

\section{Results}

Of the 169,619 questionnaires administered, 10,199 were undeliverable and 37,317 were returned, yielding an overall response rate of $23 \%$. Approximately $89 \%$ of respondents were Texas residents, $91 \%$ were white, and $96 \%$ were male. The mean age of respondents was 52 , and the median age was 53. Sixty-five percent of respondents had an average household income greater than $\$ 100,000$, and $58 \%$ had completed a bachelor's degree or higher. According to information provided by TPWD, our sample was largely representative of the study population. The mean age of all licensed Texas hunters during the 2018-2019 hunting year was 52, 89\% were male, and 94\% were Texas residents, indicating that our sample had a slightly greater proportion of males and out-of-state residents than the study population.

\subsection{Descriptive statistics of key concepts}

Results showed a relatively low level of tolerance for wild pigs overall. Approximately $20 \%$ of respondents would like to see the wild pig population in Texas completely removed, $63 \%$ would like to see numbers reduced, $14 \%$ would like to see numbers remain the same size, and $2 \%$ would like to see numbers increased. Seventy-three percent of respondents indicated they had hunted wild pigs, 48\% owned or managed land in Texas, and $32 \%$ of respondents who owned or managed land reported having experienced negative impacts on their property in the past year. Respondents' overall level of concern for different types of

Table 1

Correlation between tolerance and all independent variables.

\begin{tabular}{|c|c|c|}
\hline & & Pearson's $r$ or $r_{p b}{ }^{a}$ \\
\hline \multirow[t]{2}{*}{ Prior experience } & Hunted wild pigs ${ }^{b}$ & $0.152^{j}$ \\
\hline & Wild pig damage ${ }^{\mathrm{b}}$ & -0.174 \\
\hline Perceptions of risks & Level of concern for wild pig damage ${ }^{c}$ & $-0.386^{j}$ \\
\hline \multirow[t]{2}{*}{ Benefits } & Trapped and sold live wild pigs ${ }^{\mathrm{b}}$ & $-0.011^{j}$ \\
\hline & Provided wild pig guide and outfitting services ${ }^{b}$ & $0.047^{j}$ \\
\hline Attitudes & Attitudes toward wild pigs ${ }^{\mathrm{d}}$ & $0.702^{j}$ \\
\hline \multirow{12}{*}{ Socio-demographics } & Texas residency ${ }^{\mathrm{b}}$ & $-0.052^{j}$ \\
\hline & Age $^{e}$ & $-0.130^{j}$ \\
\hline & Gender ${ }^{\mathrm{f}}$ & $0.048^{\mathrm{j}}$ \\
\hline & Level of education ${ }^{g}$ & -0.044 \\
\hline & Average household income ${ }^{\mathrm{h}}$ & $-0.014^{\mathrm{k}}$ \\
\hline & Ethnicity: White ${ }^{\mathrm{b}}$ & $-0.007^{j}$ \\
\hline & Ethnicity: Black or African American ${ }^{b}$ & $-0.006^{j}$ \\
\hline & Ethnicity: American Indian or Alaska Native ${ }^{b}$ & $-0.006^{j}$ \\
\hline & Ethnicity: Spanish, Hispanic, or Latino ${ }^{b}$ & $-0.006^{j}$ \\
\hline & Ethnicity: Asian ${ }^{b}$ & $-0.006^{j}$ \\
\hline & Ethnicity: Native Hawaiian or Pacific Islander ${ }^{b}$ & $-0.006^{j}$ \\
\hline & Ethnicity: Other ${ }^{b}$ & $-0.006^{j}$ \\
\hline \multirow[t]{5}{*}{ Motivations } & Hunt wild pigs for meat ${ }^{i}$ & $-0.319^{j}$ \\
\hline & Hunt wild pigs for recreational purposes ${ }^{i}$ & $-0.255^{j}$ \\
\hline & Hunt wild pigs to obtain a trophy animal ${ }^{i}$ & $-0.195^{j}$ \\
\hline & Hunt wild pigs to control population ${ }^{\mathrm{i}}$ & $0.392^{j}$ \\
\hline & Hunt wild pigs to control damage ${ }^{i}$ & $0.396^{j}$ \\
\hline Preferences & Preferences for hunting wild pigs ${ }^{d}$ & $0.253^{j}$ \\
\hline Land ownership/management & Land ownership or management in Texas & $-0.129^{j}$ \\
\hline
\end{tabular}

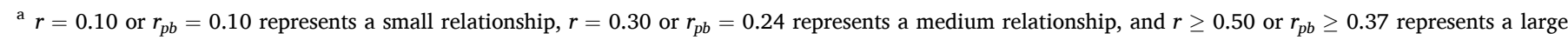
relationship (Cohen, 1988).

b Variables coded as (1) Yes, (0) No.

c Variables coded as (1) No concern, (2) Low level of concern, (3) Moderate level of concern, (4) High level of concern, (5) Very high level of concern.

d Variables coded as (1) Strongly disagree, (2) Somewhat disagree, (3) Neither agree nor disagree (4) Somewhat agree, (5) Strongly agree.

e Variable coded based on birth year.

${ }^{\mathrm{f}}$ Variable coded as (1) Male, (2) Female.

g Variable coded as (1) Did not graduate high school or receive GED, (2) High school graduate, diploma, or GED, (3) Some college, no degree, (4) Associate degree,

(5) Trade/technical/vocational training; (6) Bachelor's degree, (7) Master's degree, (8) Doctoral degree.

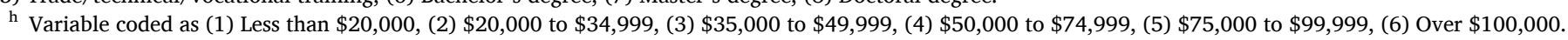

${ }^{\mathrm{i}}$ Variables coded as (1) Not at all important, (2) Not very important, (3) A little important, (4) Fairly important, (5) Very important.

j Significant at $p$-value $<0.001$.

k Significant at $p$-value $<0.05$. 
damages caused by wild pigs was generally high, with the greatest concern being damage to pastures. Reliability analysis (Cronbach's $\alpha=$ $0.94)$ supported the creation of a composite scale using these items $(M=$ 3.79) (Vaske, 2008). Eleven percent of respondents had trapped and sold live wild pigs, and $1 \%$ of respondents stated they had provided wild pig guide or outfitting services to paying hunters in 2018. Respondents' attitudes toward wild pigs were largely negative and after reverse coding the negative statements, reliability analysis (Cronbach's $\alpha=0.86$ ) supported the creation of a composite scale using these items $(M=$ 2.48). On average, the most important motivations for hunting wild pigs were to obtain a trophy animal, followed by procurement of meat. Respondents' also did not generally have a strong preference for hunting wild pigs. Reliability analysis (Cronbach's $\alpha=0.68$ ) supported the creation of a composite scale using these items $(M=1.92)$.

\subsection{Predictors of hunters' tolerance}

Results from the bivariate correlation analyses showed that seven variables had a relationship with tolerance with an effect size that met our criterion of medium to large (Table 1 ). These variables included motivation to hunt for meat, recreation, controlling the wild pig population, and controlling wild pig damage, as well as mean composites for preferences for hunting wild pigs, level of concern for damage, and attitudes toward wild pigs. Variables that did not reach the minimal effect size threshold, and were therefore removed from the model, included those under prior experience, tangible benefits, socio-demographic characteristics, and land ownership or management.

An assessment of multicollinearity showed one relationship where $r$ $>0.50$. That relationship was between motivation to hunt to control damage and motivation to hunt to control the population $(r=0.85)$. However, the VIF scores were 3.73 and 3.56 , respectively, indicating that multicollinearity was not a significant concern, and therefore both items were retained for the regression analysis.

Results from the multiple linear regression analysis provided an $R^{2}$ value of 0.527 , indicating that approximately $53 \%$ of the variance in tolerance for wild pigs could be accounted for by the combination of independent variables (Table 2). In this model, all independent variables had $95 \%$ CIs that excluded zero, indicating all values within each confidence interval were plausible values for the given parameter. Motivations to hunt for meat had a negative relationship with tolerance, indicating that respondents who placed importance on hunting wild pigs to obtain meat were less tolerant of wild pigs. Similarly, motivations to hunt wild pigs for recreational purposes had a negative relationship with tolerance, indicating that respondents who placed importance on hunting wild pigs for recreational purposes were less tolerant of wild pigs. Conversely, motivations to hunt wild pigs to control the wild pig population and damage had a positive relationship with tolerance, indicating that respondents who placed importance on hunting wild pigs to control population sizes and resulting damages were more tolerant of wild pigs. Preferences for hunting wild pigs and attitudes toward wild pigs also had a positive relationship with tolerance, indicating that respondents who preferred to hunt wild pigs and those who held more positive attitudes toward wild pigs were more tolerant of wild pigs. Lastly, level of concern for wild pig damage had a negative relationship with tolerance, indicating that respondents who had greater levels of concern were less tolerant of wild pigs. Of these seven factors, the magnitude of effect was greatest for attitudes toward wild pigs, followed by level of concern for damage.

\section{Discussion}

Overall, we found a relatively low level of tolerance for wild pigs among Texas hunters. This low level of tolerance, however, should not be interpreted as evidence that most hunters would support efforts to rid Texas of wild pigs. Importantly, most respondents (63.1\%) indicated that they would like to see the wild pig population reduced but not eliminated. This has significant implications for wild pig management in Texas, as efforts focused on eradication rather than strategic population reduction may be met with resistance from hunters. Indeed, an additional $16 \%$ of respondents indicated they would prefer to see the wild pig population remain the same or increase. Moreover, our results show that Texas hunters are not homogenous as a group when it comes to tolerance for wild pigs. The variability we found in this regard is consistent with previous studies that have found varying degrees of tolerance for wildlife (e.g., Inskip et al., 2016; Lischka et al., 2008; Skupien et al., 2016; Slagle et al., 2013; Wald and Jacobson, 2013). Our results underscore the usefulness of measuring stakeholder tolerance, as in this case it provides an important metric to guide the development of wild pig management objectives and strategies. This would entail considering hunters' social carrying capacity for wild pigs during the development of future management plans for the species.

Our results are also consistent with previous research finding that psychological factors, including beliefs, attitudes, and perceptions of risks, are important predictors of tolerance (e.g., Bruskotter et al., 2015; Inskip et al., 2016; Kansky et al., 2016; Lischka et al., 2019; Struebig et al., 2018). Most notably, respondents' attitudes toward wild pigs had the greatest association with tolerance and the greatest magnitude of effect within the regression model, followed by level of concern for wild pig damage. Based on the aforementioned research about the importance of psychological factors in predicting tolerance, and with the knowledge that there are strongly held attitudes toward wild pig management (Keuling et al., 2016; Miller, 1993; Witmer et al., 2003), it is expected that attitudes will play a key role in influencing hunters' tolerance for the species.

While improved understanding of the factors that account for differences in tolerance can help managers resolve or circumvent conflicts more successfully, it can also help them communicate more effectively (Zinn et al., 2000). Given that level of concern for wild pig damage was a key predictor of hunters' tolerance, an effective strategy for curbing behaviors linked to wild pig population spread (e.g., translocation by

Table 2

Multiple linear regression of factors affecting hunters' tolerance for wild pigs in Texas, USA. The $R^{2}$ value of this model was 0.527.

\begin{tabular}{|c|c|c|c|c|c|}
\hline \multirow[t]{3}{*}{ Variable } & \multirow[t]{3}{*}{ Unstandardized $\beta$} & \multicolumn{4}{|c|}{ Standardized values } \\
\hline & & \multirow[t]{2}{*}{$\beta$} & \multirow[t]{2}{*}{ SE } & \multicolumn{2}{|l|}{$95 \%$ CIs } \\
\hline & & & & Lower & Upper \\
\hline Intercept & 1.143 & & 0.029 & 1.085 & 1.200 \\
\hline Level of concern for wild pig damage & -0.074 & $-0.100^{\mathrm{a}}$ & 0.004 & -0.083 & -0.066 \\
\hline Attitudes toward wild pigs & 0.414 & $0.576^{\mathrm{a}}$ & 0.005 & 0.405 & 0.423 \\
\hline Motivation to hunt for meat & -0.007 & $-0.014^{\mathrm{a}}$ & 0.003 & -0.011 & -0.002 \\
\hline Motivation to hunt for recreational purposes & -0.029 & $-0.057^{\mathrm{a}}$ & 0.003 & -0.034 & -0.024 \\
\hline Motivation to hunt to control population & 0.069 & $0.097^{\mathrm{a}}$ & 0.007 & 0.056 & 0.082 \\
\hline Motivation to hunt to control damage & 0.015 & 0.022 & 0.007 & 0.003 & 0.028 \\
\hline Preferences for hunting wild pigs & 0.045 & $0.056^{\mathrm{a}}$ & 0.004 & 0.037 & 0.054 \\
\hline
\end{tabular}

a Significant at $p$-value $<0.05$. 
hunters) may involve more research-driven outreach aimed at informing hunters and other members of the public about the extent and magnitude of damages caused by wild pigs. Based upon decades of psychological research, Van der Linden et al. (2015) outlined the best practices for government agencies in framing messages to the public concerning natural resource issues. We can consider and apply these best practices to results of this study and suggest that in communicating with hunters about wild pigs in Texas, managers should 1) make it personal through affective recall (i.e., create messages that build on hunters' personal experiences with wild pigs), stories, and metaphors; 2) emphasize the current negative impacts from wild pigs while making impacts and solutions locally relevant; 3) frame solutions to wild pig issues in terms of what can be gained (not in terms of what could be lost); 4) frame messages to appeal to the values and morals of hunters; and 5) pair fear appeals with efficacy appeals (i.e., element that allows audience to have the perceived ability to make a difference through one's actions), as doing so is likely to be most effective in influencing hunters' risk perceptions.

Other psychological factors that were found to be predictors of hunters' tolerance included preferences and motivations for hunting wild pigs. Understanding motivations and preferences for engaging in activities associated with wildlife (e.g., hunting, wildlife watching) provides a unique contribution to the tolerance literature, as prior research that examines these factors is lacking. We found that respondents who were motivated to hunt wild pigs for procurement of meat or for recreational purposes were less tolerant, while respondents who were motivated to hunt to control the population and damage were more tolerant. We found this somewhat counterintuitive and might hypothesize that there may be some hunters who outwardly rationalize their hunting behavior as contributing to management even when they are equally motivated to hunt wild pigs for personal gain. Additionally, we might hypothesize that those who find it important to hunt wild pigs to control population size and damage may have lower perceived risks and higher perceived benefits associated with wild pigs. In turn, they may feel they have more personal control over the risks that wild pigs pose and/or have greater trust in managers, allowing them to be more tolerant of wild pigs on the landscape. Previous literature has shown that an increase in perceived level of personal control over risks and social trust in management agencies can raise stakeholders' tolerance indirectly through their influence on perceived risks and benefits (Bruskotter and Wilson, 2014; Zajac et al., 2012).

In contrast to the many assumptions that underlie management of negative interactions with wildlife, our study, like others, revealed that prior experience with wild pig damage was not a strong predictor of hunters' tolerance for the species (Inskip et al., 2016; Lischka et al., 2019; Majić et al., 2011; Riley and Decker, 2000). Although beyond the scope of this study, there may be underlying patterns regarding the frequency and severity of different types of wild pig damage that could better explain variation in hunters' tolerance. Similarly, experience with wild pig hunting did not have a significant effect on hunters' tolerance. Further, while previous studies have found individuals' tolerance for wildlife can be negatively affected by the species' proximity to human dwellings and territories (Kleiven et al., 2004; Riley and Decker, 2000; Zimmermann et al., 2005), owning or managing land in Texas did not prove to be a strong predictor of hunters' tolerance for wild pigs.

While recent studies found that perceptions of benefits associated with wildlife played an important and often key role in affecting tolerance toward wildlife (Bruskotter and Wilson, 2014; Lischka et al., 2019; Zajac et al., 2012), our study found that benefits attributed to wild pig-hunting-related activities were not strong predictors of hunters' tolerance. This could possibly be explained by the relatively small proportion of respondents who stated that they trapped and sold live wild pigs $(11 \%)$ or provided guide and outfitting services to paying hunters (1\%). More likely, this could be due to differences in how we operationalized benefits (i.e., tangible, monetary benefits) compared to previous research that included intangible benefits (e.g., convenience of hunting wild pigs or existence value of having them on the landscape). However, we might also hypothesize that hunters believe that the risks wild pigs pose outweigh any personal monetary benefits they receive in connection with wild pig hunting and trapping. Economic benefits associated with hunting might also be less important to hunters than other tangible, non-monetary benefits.

Future research would benefit from expanding on this topic and by addressing certain limitations found in this study. While our model explained approximately $53 \%$ of the variation in tolerance, our understanding may be improved by investigating additional factors shown through prior research to affect tolerance for other wildlife species. These factors include, for example, perceptions of tangible, nonmonetary benefits, as well as intangible benefits associated with wild pigs, wildlife value orientations, trust in management agencies, and perceived level of personal control over risks (Bruskotter and Wilson, 2014; Lischka et al., 2019). There is also a need to further explore the relationship between hunters' tolerance and perceived risks, often measured by having respondents rate the perceived likelihood and severity of various risks (Loewenstein et al., 2001). We recognize that in our study, level of concern for wild pig damage was the only indicator (i. e., emotion-related indicator) of this concept. Similarly, it would be advantageous to further assess how type, frequency, and severity of wild pig damage affects tolerance among hunters, including those who do not own or manage land. We also recommend future research on behavioral measures of tolerance (e.g., trapping and relocating wild pigs for future hunting opportunities) to provide additional information beyond that obtained from general attitudinal measures such as wildlife acceptance capacity. Lastly, there is a need to investigate hunters' tolerance for wild pigs in other parts of the world and within other states in the United States, as well as among other stakeholder groups to assess competing interests (Organ and Ellingwood, 2000).

This study provides unique contributions to the broader literature on tolerance for wildlife by going beyond typical applications of the concept in conservation to include tolerance for non-native and invasive species. Our findings also provide practical information to help guide wild pig management efforts. Management of wild pigs is a challenging and complex endeavor. The future success of management efforts will depend in part on the level of tolerance for the species, particularly in places like Texas where some stakeholders view wild pigs as a valuable resource. Results of this research can inform wild pig management plans that are in alignment with stakeholders' preferences, thereby reducing the potential for stakeholder conflict. Further, our findings suggest that communication and outreach efforts should continue to highlight the negative impacts of wild pigs and the necessity of reducing the wild pig population in Texas to mitigate these impacts. Future research and development of wild pig management strategies that incorporate an understanding of stakeholder tolerance and related factors will be vital in ensuring effective management of this species.

\section{Declaration of competing interest}

The authors declare that they have no known competing financial interests or personal relationships that could have appeared to influence the work reported in this paper.

\section{Acknowledgements}

We wish to thank Texas A\&M AgriLife Extension Service and the Texas State Legislature for their support of this study. We also thank Texas Parks and Wildlife Department for their collegiality and collaboration in obtaining contact information for licensed hunters in Texas, as well as all the Texas hunters who took the time to participate in this research. Lastly, a special thanks to Mr. Michael J. Bodenchuk, Texas Wildlife Services state director, for his vital contributions to formation of this survey. 


\section{Appendix A. Supplementary data}

Supplementary data to this article can be found online at https://doi. org/10.1016/j.jenvman.2021.112143.

\section{Funding}

This work was supported by Texas A\&M AgriLife Extension Service, College Station, TX, USA.

\section{Disclosure statement}

The authors report no conflicts of interest.

\section{Data availability}

Participants of this study did not agree for their data to be shared publicly, so supporting data is not available.

\section{Disclaimer}

The findings and conclusions in this publication are those of the authors and should not be construed to represent any official USDA, U.S. Government determination or policy, nor does it represent those of Texas A\&M AgriLife Extension Service, the Texas A\&M University System, or the State of Texas.

\section{CRediT author statement}

Hailey E. McLean: Conceptualization, Methodology, Validation, Formal analysis, Investigation, Resources, Data curation, Writing original draft, Writing - review \& editing, Supervision, Visualization, Project administration, Tara L. Teel: Conceptualization, Methodology, Validation, Formal analysis, Investigation, Writing - original draft, Writing - review \& editing, Supervision, Alan D. Bright: Conceptualization, Methodology, Validation, Formal analysis, Investigation, Writing - original draft, Writing - review \& editing, Supervision, Lauren M. Jaebker: Conceptualization, Validation, Data curation, Writing review \& editing, John M. Tomecek: Conceptualization, Validation, Investigation, Resources, Data curation, Writing - review \& editing, Supervision, Funding acquisition, Maureen G. Frank: Conceptualization, Validation, Investigation, Data curation, Writing - review \& editing, Funding acquisition, Rachael L. Connally: Conceptualization, Validation, Investigation, Data curation, Writing - review \& editing, Funding acquisition, Stephanie A. Shwiff: Supervision, Funding acquisition, Keith M. Carlisle: Conceptualization, Validation, Investigation, Data curation, Writing - review \& editing, Supervision, Project administration.

\section{References}

Anderson, A., Slootmaker, C., Harper, E., Holderieath, J., Shwiff, S.A., 2016. Economic estimates of feral swine damage and control in 11 US states. Crop Protect. 89, 89-94.

Beasley, J.C., Ditchkoff, S.S., Mayer, J.J., Smith, M.D., Vercauteren, K.C., 2018. Research priorities for managing invasive wild pigs in North America. J. Wildl. Manag. 82 (4), 674-681.

Belden, R., Frankenberger, W., 1977. Management of Feral Hogs in Florida-Past, Present, and Future. Clemson University.

Bevins, S.N., Pedersen, K., Lutman, M.W., Gidlewski, T., Deliberto, T.J., 2014. Consequences associated with the recent range expansion of nonnative feral swine. Bioscience 64 (4), 291-299.

Boumendjel, F.Z., Hajji, G.E.M., Valqui, J., Bouslama, Z., 2016. The hunting trends of wild boar (Sus scrofa) hunters in northeastern Algeria. Wildlife Biol. Prac. 12 (2), $1-13$.

Bruskotter, J.T., Fulton, D.C., 2012. Will hunters steward wolves? A comment on Treves and Martin. Soc. Nat. Resour. 25 (1), 97-102.

Bruskotter, J.T., Wilson, R.S., 2014. Determining where the wild things will be: using psychological theory to find tolerance for large carnivores. Conserv. Lett. 7 (3), 158-165.
Bruskotter, J.T., Singh, A., Fulton, D.C., Slagle, K., 2015. Assessing tolerance for wildlife: clarifying relations between concepts and measures. Hum. Dimens. Wildl. 20 (3), 255-270.

Burger, J., Sanchez, J., Gibbons, J.W., Gochfeld, M., 1998. Gender differences in recreational use, environmental attitudes, and perceptions of future land use at the Savannah River site. Environ. Behav. 30 (4), 472-486.

Carpenter, L.H., Decker, D.J., Lipscomb, J.F., 2000. Stakeholder acceptance capacity in wildlife management. Hum. Dimens. Wildl. 5 (3), 5-19.

Caudell, J.N., Dowell, E., Welch, K., 2016. Economic utility for the anthropogenic spread of wild hogs. Human-Wildlife Interact. 10 (2), 230-239.

Cohen, J., 1988. Statistical Power Analysis for the Behavioral Sciences. Erlbaum.

Corn, J.L., Jordan, T.R., 2017. Development of the national feral swine map, 1982-2016. Wildl. Soc. Bull. 41 (4), 758-763.

Decker, D.J., Purdy, K.G., 1988. Toward a concept of wildlife acceptance capacity in wildlife management. Wildl. Soc. Bull. 16 (1), 53-57.

Desbiez, A.L.J., Keuroghlian, A., Piovezan, U., Bodmer, R.E., 2011. Invasive species and bushmeat hunting contributing to wildlife conservation: the case of feral pigs in a Neotropical wetland. Oryx 45 (1), 78-8.

Fishbein, M., Ajzen, I., 2010. Predicting and Changing Behavior. Psychology Press.

Gore, M.L., Knuth, B.A., Curtis, P.D., Shanahan, J.E., 2006. Stakeholder perceptions of risk associated with human-black bear conflicts in New York's Adirondack Park campgrounds: implications for theory and practice. Wildl. Soc. Bull. 34 (1), 36-43.

Grady, M.J., Harper, E.E., Carlisle, K.M., Ernst, K.H., Shwiff, S.A., 2019. Assessing public support for restrictions on transport of invasive wild pigs (Sus scrofa) in the United States. J. Environ. Manag. 237, 488-494.

Inskip, C., Carter, N., Riley, S., Roberts, T., MacMillan, D., 2016. Toward humancarnivore coexistence: understanding tolerance for tigers in Bangladesh. PloS One 11 (1), 1-20.

Kansky, R., Kidd, M., Knight, A.T., 2016. A wildlife tolerance model and case study for understanding human wildlife conflicts. Biol. Conserv. 201, 137-145.

Keuling, O., Strauß, E., Siebert, U., 2016. Regulating wild boar populations is "somebody else's problem"! - human dimension in wild boar management. Sci. Total Environ. 554, 311-319.

Kinsey, J.C., 2020. Ecology and Management of Wild Pigs. Texas Parks and Wildlife Department.

Kleiven, J., Bjerke, T., Kaltenborn, B.P., 2004. Factors influencing the social acceptability of large carnivore behaviours. Biodivers. Conserv. 13, 1647-1658.

Lewis, J.S., Corn, J.L., Mayer, J.J., Jordan, T.R., Farnsworth, M.L., Burdett, C.L., VerCauteren, K.C., Sweeney, S.J., Miller, R.S., 2019. Historical, current, and potential population size estimates of invasive wild pigs (Sus scrofa) in the United States. Biol. Invasions 21 (7), 2373-2384.

Lischka, S.A., Riley, S.J., Rudolph, B.A., 2008. Effects of impact perception on acceptance capacity for white-tailed deer. J. Wildl. Manag. 72 (2), 502-509.

Lischka, S.A., Teel, T.L., Johnson, H.E., Crooks, K.R., 2019. Understanding and managing human tolerance for a large carnivore in a residential system. Biol. Conserv. 238 (108189), 1-9.

Loewenstein, G.F., Weber, E.U., Hsee, C.K., Welch, N., 2001. Risk as feelings. Psychol. Bull. 127, 267-286.

Lowe, S., Browne, M., Boudjelas, S., De Poorter, M., 2000. 100 of the World's Worst Invasive Alien Species: A Selection from the Global Invasive Species Database, vol. 12. IUCN.

Maguire, L.A., Jenkins, P., Nugent, G., 1997. Research as a route to consensus? Feral ungulate control in Hawaii. In: Paper Presented at the North American Wildlife and Natural Resources Conference, Missouri.

Majić, A., de Bodonia, A.M.T., Huber, Đ., Bunnefeld, N., 2011. Dynamics of public attitudes toward bears and the role of bear hunting in Croatia. Biol. Conserv. 144 (12), 3018-3027.

Mayer, J.J., Brisbin, I.L., 2008. Wild Pigs in the United States: Their History, Comparative Morphology, and Current Status. University of Georgia Press.

McKee, S., Anderson, A., Carlisle, K., Shwiff, S.A., 2020. Economic estimates of invasive pig damage to crops in 12 US states. Crop Protect. 132 (105105), 1-12.

Miller, J., 1993. A national perspective on feral swine. In: Hanselka, C., Cadenhead, J. (Eds.), Feral Swine: A Compendium for Resource Managers. Texas Agricultural Extension Service, pp. 9-16.

Morzillo, A.T., Needham, M.D., 2015. Landowner incentives and normative tolerances for managing beaver impacts. Hum. Dimens. Wildl. 20 (6), 514-530.

Oliver, W., Leus, K., 2008. Feral Pigs (Sus scrofa). https://doi.org/10.2305/IUCN UK.2008.RLTS.T41775A10559847.en.

Organ, J.F., Ellingwood, M.R., 2000. Wildlife stakeholder acceptance capacity for black bears, beavers, and other beasts in the east. Hum. Dimens. Wildl. 5 (3), 63-75.

Organ, J.F., Geist, V., Mahoney, S.P., Williams, S., Krausman, P.R., Batcheller, G.R., Decker, T.A., Carmichael, R., Nanjappa Regan, R., Medellin, R.A., Cantu, R., McCabe, R.E., Craven, S., Vecellio, G.M., Decker, D.J., 2012. The North American model of wildlife conservation. Wildlife Soc. Tech. Rev. 12 (4).

Texas Parks and Wildlife Department (TPWD), 2020. Nongame, Exotic, Endangered, Threatened \& Protected Species. https://tpwd.texas.gov/regulations/outdoor-annua 1/hunting/nongame-and-other-species.

Peine, J.D., Farmer, J.A., 1990. Wild Hog Management Program at Great Smoky Mountains National Park. In: Paper Presented at the Fourteenth Vertebrate Pest Conference, California.

Pejchar, L., Mooney, H.A., 2009. Invasive species, ecosystem services and human wellbeing. Trends Ecol. Evol. 24 (9), 497-504.

Pimental, D., 2007. Environmental and economic costs of vertebrate species invasions into the United States. Manag. Vertebr. Invas. Spec. 38, 2-8.

Riley, S.J., Decker, D.J., 2000. Wildlife stakeholder acceptance capacity for cougars in Montana. Wildl. Soc. Bull. 28 (4), 931-939. 
Rosa, C. A. Da, Wallau, M.O., Pedrosa, F., 2018. Hunting as the main technique used to control wild pigs in Brazil. Wildl. Soc. Bull. 42 (1), 111-118.

Siegrist, M., Cvetkovich, G., 2000. Perception of hazards: the role of social trust and knowledge. Risk Anal. (20), 713-720.

Sjöberg, L., 2000. Factors in risk perception. Risk Anal. 20 (1), 1-12.

Skupien, G.M., Andrews, K.M., Larson, L.R., 2016. Teaching tolerance? Effects of conservation education programs on wildlife acceptance capacity for the American alligator. Hum. Dimens. Wildl. 21 (3), 264-279.

Slagle, K., Zajac, R., Bruskotter, J., Wilson, R., Prange, S., 2013. Building tolerance for bears: a communications experiment. J. Wildl. Manag. 77 (4), 863-869.

Southeastern Association of Fish and Wildlife Agencies Wild Hog Working Group (SEAFWA-WHWG), 2016. Annual State Summary Report.

Struebig, M.J., Linkie, M., Deere, N.J., Martyr, D.J., Millyanawati, B., Faulkner, S.C., Le Comber, S.C., Mangunjaya, F.M., Leader-Williams, N., McKay, J.E., St John, F.A.V. 2018. Addressing human-tiger conflict using socio-ecological information on tolerance and risk. Nat. Commun. 9 (1), 3455.

Sutherland, W., Adams, W., Aronson, R., Aveling, R., Blackburn, T., Broad, S., Da Fonseca, G., 2009. One hundred questions of importance to the conservation of global biological diversity. Conserv. Biol. 23 (3), 557-567.

Ueda, G., Kanzaki, N., 2005. Wild boar hunters profile in Shimane Prefecture, western Japan. Wildlife Biol. Prac. 1 (2), 146-151.

U.S. Department of Agriculture (USDA), 2019. History of Feral Swine in the Americas. htt ps://www.aphis.usda.gov/aphis/ourfocus/wildlifedamage/operational-activitie s/feral-swine/sa-fs-history.
Van der Linden, S., Maibach, E., Leiserowitz, A., 2015. Improving public engagement with climate change: five "best practice" insights from psychological science. Perspect. Psychol. Sci. 10 (6), 758-763.

Vaske, J.J., 2008. Survey Research and Analysis: Applications in Parks, Recreation and Human Dimensions. Venture Publishing, Inc.

Wald, D.M., Jacobson, S.K., 2013. Factors affecting student tolerance for free-roaming cats. Hum. Dimens. Wildl. 18 (4), 263-278.

Weeks, P., Packard, J., 2009. Feral hogs: invasive species or nature's bounty? Hum. Organ. 68 (3), 280-292.

Witmer, G.W., Sanders, R.B., Taft, A.C., 2003. Feral swine - are they a disease threat to livestock in the United States? Michigan Bovine Tuberculosis Bibliogr. Datab. 113, 316-325.

Zajac, R.M., Bruskotter, J.T., Wilson, R.S., Prange, S., 2012. Learning to live with black bears: a psychological model of acceptance. J. Wildl. Manag. 76 (7), 1331-1340.

Zar, J.H., 1999. Biostatistical Analysis, fourth ed. Pearson Education India.

Zimmermann, A., Walpole, M.J., Leader-Williams, N., 2005. Cattle ranchers' attitudes to conflicts with jaguar (Panthera onca) in the Pantanal of Brazil. Oryx 39, 406-412.

Zinn, H.C., Manfredo, M.J., Vaske, J.J., 2000. Social psychological bases for stakeholder acceptance capacity. Hum. Dimens. Wildl. 5 (3), 20-33.

Zivin, J., Hueth, B.M., Zilberman, D., 2000. Managing a multiple-use resource: the case of feral pig management in California rangeland. J. Environ. Econ. Manag. 39 (2), 189-204. 